\title{
Comparison of Two Radiotherapy Regimens for Metastatic Spinal Cord Compression: Subgroup Analyses from a Randomized Trial
}

\author{
DIRK RADES ${ }^{1}$, ANTONIO J. CONDE-MORENO ${ }^{2}$, JON CACICEDO ${ }^{3}$, BARBARA ŠEGEDIN ${ }^{4}$, \\ KARMEN STANIC ${ }^{4}$, MICHAELA METZ ${ }^{5}$, VOLKER RUDAT ${ }^{6}$ and STEVEN E. SCHILD ${ }^{7}$ \\ ${ }^{1}$ Department of Radiation Oncology, University of Lübeck, Lübeck, Germany; \\ ${ }^{2}$ Department of Radiation Oncology, Consorcio Hospital Provincial de Castellón, Castellón, Spain; \\ ${ }^{3}$ Department of Radiation Oncology, Cruces University Hospital, Barakaldo, Spain; \\ ${ }^{4}$ Department of Radiotherapy, Institute of Oncology Ljubljana, Ljubljana, Slovenia; \\ ${ }^{5}$ Department of Radiation Oncology, University of Würzburg, Würzburg, Germany; \\ ${ }^{6}$ Department of Radiation Oncology, Saad Specialist Hospital, Al-Khobar, Kingdom of Saudi Arabia; \\ ${ }^{7}$ Department of Radiation Oncology, Mayo Clinic, Scottsdale, AZ, U.S.A.
}

\begin{abstract}
Background/Aim: According to our randomized trial, $5 \times 4 G y$ was comparable to $10 \times 3 G y$ for metastatic spinal cord compression. Since it remained unclear whether findings applied to poor and intermediate prognoses patients, subgroup analyses were performed. Patients and Methods: In patients with poor prognoses, 58 received $5 \times 4 G y, 53$ received $10 \times 3 G y$. In intermediate-prognoses patients, numbers were 43 and 49. Results: In patients with poor prognoses, 1-month overall response (OR) was $85 \%$ after $5 \times 4 G y$ and $10 \times 3 G y(p=0.99)$, improvement $38 \%$ vs. $42 \%$, ambulatory status $60 \%$ vs. $64 \%$ ( $p=0.83)$, 6-month local progression-free survival (LPFS) $75 \%$ vs. 69\% $(p=0.74)$ and 6 -month overall survival (OS) $26 \%$ vs. $19 \%$ $(p=0.43)$. In patients with intermediate prognoses, 1 -month OR was $89 \%$ after $5 \times 4 G y$ and $93 \%$ after $10 \times 3 G y(p=0.85)$, improvement $39 \%$ vs. $45 \%$, ambulatory status $84 \%$ vs. $82 \%$ ( $p=0.90)$, 6-month LPFS $79 \%$ vs. 92\% $(p=0.17)$ and 6months OS $65 \%$ vs. 58\% ( $p=0.65)$. Conclusion: $5 \times 4 G y$ was not significantly inferior to 10x3Gy in both subgroups.
\end{abstract}

Metastatic spinal cord compression (MSCC) is an oncologic emergency that affects $5-10 \%$ of adult cancer patients during

Correspondence to: Prof Dirk Rades, Department of Radiation Oncology, University of Lübeck, Lübeck, Ratzeburger Allee 160, 23538 Lübeck, Germany. Tel: +49 451 5006661, Fax: +49 451 5003324, e-mail: rades.dirk@gmx.net

Key Words: Metastatic spinal cord compression, radiotherapy, randomized trial, survival prognosis, subgroup analyses, treatment outcomes. their disease course $(1,2)$. Radiotherapy alone is the most frequently used treatment, although upfront decompressive surgery became more popular after a randomized trial published in 2005 had shown that highly selected patients benefit from the addition of surgery in terms of a higher ambulation and survival rates (3). Patients irradiated for MSCC often have a median survival of only 2 to 6 months (1, 2). Radiotherapy sessions can be burdensome for the patients who are generally impaired by vertebral pain and neurologic deficits. Thus, the number of fractions should be kept as low as possible while producing positive outcomes. During the last three years, three randomized trials became available that compared two different radiation regimens for MSCC. At this year's annual ASCO meeting, the most recent one, the SCORAD III trial, was presented with 688 patients from the United Kingdom and Australia (4). This trial compared 1×8Gy to short-course multi-fraction radiotherapy with $5 \times 4 \mathrm{~Gy}$ over 1 week in patients with a poor survival prognosis, i.e. a median survival time of only 13 weeks. According to the SCORAD III trial, $1 \times 8$ Gy was not inferior to $5 \times 4 \mathrm{~Gy}$ with respect to the ability to walk at 8 weeks following randomization. In another trial (ICORG 05-03) published in abstract form in $2014,1 \times 10 \mathrm{~Gy}$ was not inferior to $5 \times 4 \mathrm{~Gy}$ for overall response (OR), defined as improvement or no further progression of motor deficits, and for ambulation at 5 weeks (5). The third randomized trial (SCORE-2) was published as a full paper in January 2016 (6). It compared the two most common radiotherapy regimens, $5 \times 4 \mathrm{~Gy}$ over 1 week and $10 \times 3$ Gy over 2 weeks in patients with a poor or intermediate survival prognosis. According to the results of the SCORE-2 trial, $5 \times 4$ Gy was not inferior to $10 \times 3$ Gy regarding OR, effect on motor function, post-treatment ambulatory status, local 
Table I. Characteristics of the group of patients with a poor survival prognosis.

\begin{tabular}{|c|c|c|c|}
\hline & $\begin{array}{c}5 \times 4 \mathrm{~Gy} \\
\mathrm{~N} \text { patients } \\
(\%)\end{array}$ & $\begin{array}{c}10 \times 3 \mathrm{~Gy} \\
\mathrm{~N} \text { patients } \\
(\%)\end{array}$ & $p$-Value \\
\hline \multicolumn{4}{|l|}{ Age } \\
\hline$\leq 68$ years $(N=67)$ & $36(62)$ & $31(58)$ & \\
\hline$\geq 69$ years $(\mathrm{N}=44)$ & $22(38)$ & $22(42)$ & 0.81 \\
\hline \multicolumn{4}{|l|}{ Gender } \\
\hline Female $(\mathrm{N}=40)$ & $24(41)$ & $16(30)$ & \\
\hline Male $(\mathrm{N}=71)$ & $34(59)$ & $37(70)$ & 0.46 \\
\hline \multicolumn{4}{|l|}{ ECOG performance status } \\
\hline $1-2(\mathrm{~N}=28)$ & $15(26)$ & $13825)$ & \\
\hline $3-4(\mathrm{~N}=83)$ & $43(74)$ & $40(75)$ & 0.93 \\
\hline \multicolumn{4}{|l|}{ Type of primary tumor } \\
\hline Breast cancer $(\mathrm{N}=3)$ & $3(5)$ & $0(0)$ & \\
\hline Prostate cancer $(\mathrm{N}=10)$ & $4(7)$ & $6(11)$ & \\
\hline Myeloma/lymphoma $(\mathrm{N}=4)$ & $3(5)$ & $1(82)$ & \\
\hline Lung cancer $(\mathrm{N}=46)$ & $24(41)$ & $22(42)$ & \\
\hline Other tumors $(\mathrm{N}=48)$ & $24(41)$ & $24(45)$ & 0.75 \\
\hline \multicolumn{4}{|l|}{ Involved vertebrae (n) } \\
\hline $1-2(\mathrm{~N}=57)$ & $28(48)$ & $29(55)$ & \\
\hline$\geq 3(\mathrm{~N}=54)$ & $30(52)$ & $24(45)$ & 0.63 \\
\hline \multicolumn{4}{|l|}{$\begin{array}{l}\text { Other bone metastases at } \\
\text { the time of radiotherapy }\end{array}$} \\
\hline No $(\mathrm{N}=14)$ & $8(14)$ & $6(11)$ & \\
\hline Yes $(\mathrm{N}=97)$ & $50(86)$ & $47(89)$ & 0.89 \\
\hline \multicolumn{4}{|l|}{$\begin{array}{l}\text { Visceral metastases at } \\
\text { the time of radiotherapy }\end{array}$} \\
\hline No $(\mathrm{N}=12)$ & $5(9)$ & $7(13)$ & \\
\hline Yes $(\mathrm{N}=99)$ & $53(91)$ & $46(87)$ & 0.79 \\
\hline \multicolumn{4}{|l|}{$\begin{array}{l}\text { Interval from tumor } \\
\text { diagnosis to MESCC }\end{array}$} \\
\hline$\leq 5$ months $(\mathrm{N}=70)$ & $36(62)$ & $34(64)$ & \\
\hline$>5$ months $(\mathrm{N}=41)$ & $22(38)$ & $19(36)$ & 0.89 \\
\hline \multicolumn{4}{|l|}{$\begin{array}{l}\text { Administration of bisphosphonates } \\
\text { or denosumab }\end{array}$} \\
\hline No $(\mathrm{N}=72)$ & $36(62)$ & $36(68)$ & \\
\hline Yes $(\mathrm{N}=39)$ & $22(38)$ & $17(32)$ & 0.71 \\
\hline \multicolumn{4}{|l|}{ Ambulatory prior to radiotherapy } \\
\hline Ambulatory without aid $(\mathrm{N}=21)$ & $11(19)$ & $10(19)$ & \\
\hline Ambulatory with aid $(\mathrm{N}=30)$ & $16(28)$ & $14(26)$ & \\
\hline Not ambulatory $(\mathrm{N}=60)$ & $31(53)$ & $29(55)$ & $>0.99$ \\
\hline \multicolumn{4}{|l|}{$\begin{array}{l}\text { Time developing motor } \\
\text { deficits prior to radiotherapy }\end{array}$} \\
\hline $1-7$ days $(\mathrm{N}=63)$ & $35(60)$ & $28(53)$ & \\
\hline 8-14 days $(\mathrm{N}=19)$ & $9(16)$ & $10(19)$ & \\
\hline$>14$ days $(\mathrm{N}=29)$ & $14(24)$ & $15(28)$ & 0.86 \\
\hline
\end{tabular}

progression-free survival (LPFS) and overall survival (OS). The patients' prognosis was estimated with a validated scoring tool (7). In the cohort used to create this tool, median survival times were 2.5 months in the poor-prognosis group and 5.5 months in the intermediate-prognosis group. Looking at this difference, it may be possible that the non-inferiority of $5 \times 4 G y$ in the SCORE-2 trial is only limited to patients in
Table II. Characteristics of the group of patients with an intermediate survival prognosis.

\begin{tabular}{|c|c|c|c|}
\hline & $\begin{array}{c}5 \times 4 \mathrm{~Gy} \\
\text { N patients } \\
(\%)\end{array}$ & $\begin{array}{c}10 \times 3 \mathrm{~Gy} \\
\text { N patients } \\
(\%)\end{array}$ & $p$-Value \\
\hline \multicolumn{4}{|l|}{ Age } \\
\hline$\leq 68$ years $(\mathrm{N}=36)$ & $16(37)$ & $20(41)$ & \\
\hline$\geq 69$ years $(\mathrm{N}=56)$ & $27(63)$ & $29(59)$ & 0.83 \\
\hline \multicolumn{4}{|l|}{ Gender } \\
\hline Female $(\mathrm{N}=39)$ & $17(40)$ & $22(45)$ & \\
\hline Male $(\mathrm{N}=53)$ & $26(60)$ & $27(55)$ & 0.74 \\
\hline \multicolumn{4}{|l|}{ ECOG performance status } \\
\hline $1-2(\mathrm{~N}=41)$ & $16(37)$ & $25(51)$ & \\
\hline $3-4(N=51)$ & $27(63)$ & $24(49)$ & 0.37 \\
\hline \multicolumn{4}{|l|}{ Type of primary tumor } \\
\hline Breast cancer $(\mathrm{N}=29)$ & $13(30)$ & $16(33)$ & \\
\hline Prostate cancer $(\mathrm{N}=22)$ & $12(28)$ & $10(20)$ & \\
\hline Myeloma/lymphoma $(\mathrm{N}=12)$ & $5(12)$ & $7(14)$ & \\
\hline Lung cancer $(\mathrm{N}=12)$ & $5(12)$ & $7(14)$ & \\
\hline Other tumors $(\mathrm{N}=17)$ & $8(19)$ & $9(18)$ & 0.98 \\
\hline \multicolumn{4}{|l|}{ Involved vertebrae (n) } \\
\hline $1-2(\mathrm{~N}=54)$ & $27(63)$ & $27(55)$ & \\
\hline$\geq 3(\mathrm{~N}=38)$ & $16(37)$ & $22(45)$ & 0.62 \\
\hline \multicolumn{4}{|l|}{$\begin{array}{l}\text { Other bone metastases at } \\
\text { the time of radiotherapy }\end{array}$} \\
\hline No $(\mathrm{N}=14)$ & $5(12)$ & $9(18)$ & \\
\hline Yes $(\mathrm{N}=78)$ & $38(88)$ & $40(82)$ & 0.73 \\
\hline \multicolumn{4}{|l|}{$\begin{array}{l}\text { Visceral metastases at } \\
\text { the time of radiotherapy }\end{array}$} \\
\hline No $(\mathrm{N}=34)$ & $18(42)$ & $16(33)$ & \\
\hline Yes $(\mathrm{N}=58)$ & $25(58)$ & $33(67)$ & 0.58 \\
\hline \multicolumn{4}{|l|}{$\begin{array}{l}\text { Interval from tumor } \\
\text { diagnosis to MESCC }\end{array}$} \\
\hline$\leq 5$ months $(\mathrm{N}=36)$ & $19(44)$ & $17(35)$ & \\
\hline$>5$ months $(\mathrm{N}=56)$ & $24(56)$ & $32(65)$ & 0.56 \\
\hline \multicolumn{4}{|l|}{$\begin{array}{l}\text { Administration of bisphosphonates } \\
\text { or denosumab }\end{array}$} \\
\hline No $(\mathrm{N}=47)$ & $23(53)$ & $24(49)$ & \\
\hline Yes $(\mathrm{N}=45)$ & $20(43)$ & $25(51)$ & 0.77 \\
\hline \multicolumn{4}{|l|}{ Ambulatory prior to radiotherapy } \\
\hline Ambulatory without aid $(\mathrm{N}=31)$ & $15(35)$ & $16(33)$ & \\
\hline Ambulatory with aid $(\mathrm{N}=35)$ & $16(37)$ & $19(39)$ & \\
\hline Not ambulatory $(\mathrm{N}=26)$ & $12(28)$ & $14(29)$ & 0.99 \\
\hline \multicolumn{4}{|l|}{$\begin{array}{l}\text { Time developing motor deficits } \\
\text { prior to radiotherapy }\end{array}$} \\
\hline $1-7$ days $(\mathrm{N}=29)$ & $11(26)$ & $18(37)$ & \\
\hline $8-14$ days $(N=34)$ & $17(40)$ & $17(35)$ & \\
\hline$>14$ days $(\mathrm{N}=29)$ & $15(35)$ & $14(29)$ & 0.72 \\
\hline
\end{tabular}

either the intermediate- or the poor-prognosis group. This hypothesis is supported by a previous prospective study showing that short-course regimens including $5 \times 4 \mathrm{~Gy}$ are associated with more in-field recurrences of MSCC than longer-course regimens including $10 \times 3 \mathrm{~Gy}$ (8). The risk of developing such a recurrence increases with lifetime. Thus, it is reasonable to perform separate subgroup analyses in the 


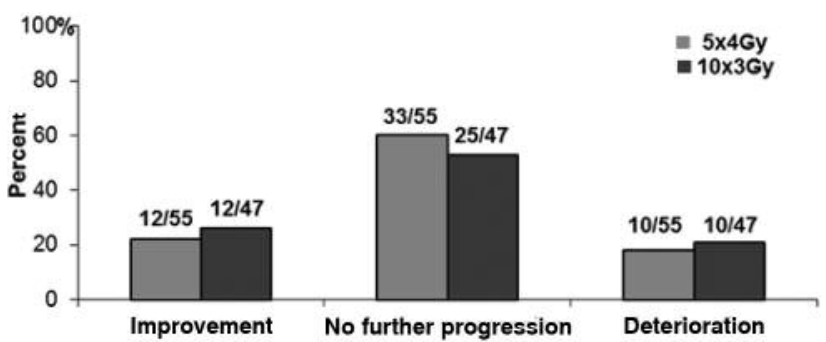

Effect on motor function directly after RT $(p=0.95)$

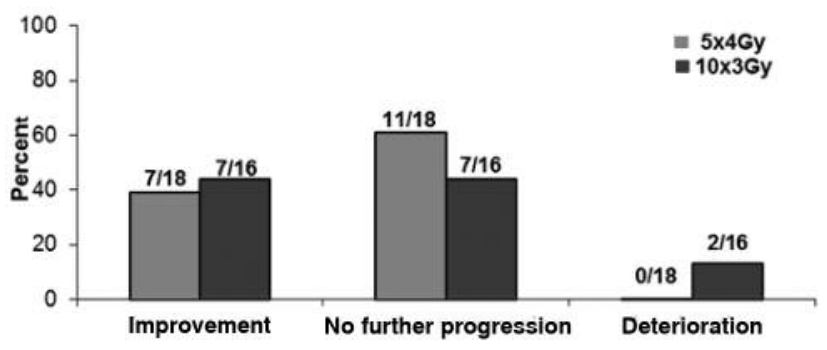

Effect on motor function at 3 months after $\mathrm{RT}(\mathrm{p}=\mathbf{0 . 8 7 )}$

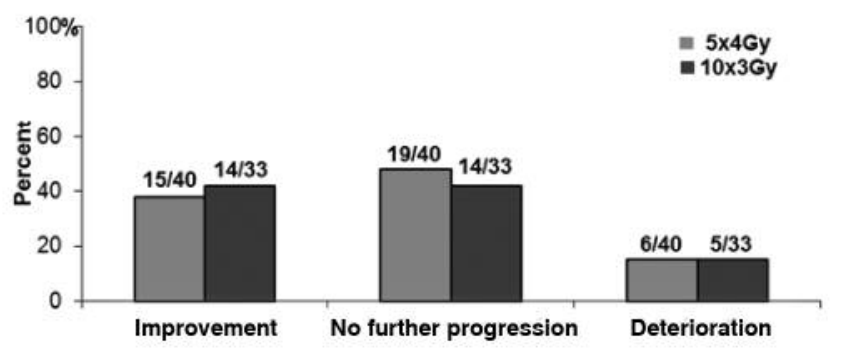

Effect on motor function at 1 month after RT $(p=0.74)$

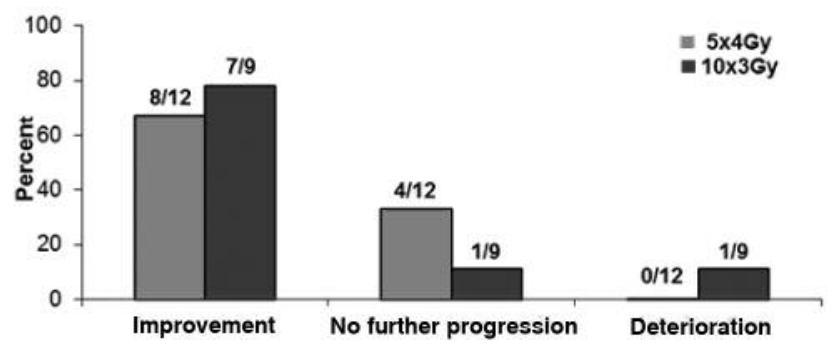

Effect on motor function at 6 months after RT $(p=0.71)$

Figure 1. Patients with poor survival prognoses: Comparison of $5 \times 4 G y$ and $10 \times 3 G y$ for the effect on motor function (improvement, no further progression, deterioration) directly (A), at 1 month (B), at 3 months (C), and at 6 months (D) after radiotherapy.

cohort of the SCORE-2 trial for patients with poor estimated survival and those with intermediate prognoses.

\section{Patients and Methods}

The SCORE-2 trial compared $5 \times 4$ Gy over 1 week to $10 \times 3$ Gy over 2 weeks in patients with MSCC and a poor or intermediate survival prognosis (6) with respect to OR defined as improvement or at least no further progression of motor deficits, effect of radiotherapy on motor deficits, post-treatment ambulatory status, LPFS and OS. The SCORE2 trial was approved by local ethic committees (leading committee: University of Lübeck), the expert committee of the German Society for Radiation Oncology and the German Cancer Society. It was performed in accord with an assurance filed with and in accordance with the precepts established by the Helsinki Declaration. Criteria for inclusion and exclusion, diagnostic procedures, radiation techniques and radiation parameters have been previously described (6). After written informed consent, 203 patients irradiated for MSCC between 07/2010 and $05 / 2015$, were stratified for pre-treatment ambulatory status, time developing motor deficits prior to radiotherapy, and primary tumor type, and randomly assigned to $5 \times 4 \mathrm{~Gy}$ or $10 \times 3 \mathrm{~Gy}$.

Motor function was graded with an 8-point scale (9): 0, complete paraplegia; 1, palpable/visible muscle contractions; 2, active movement of the leg without gravity; 3 , against gravity; 4, against mild resistance; 5, against intermediate resistance; 6 , against strong resistance; and 7, normal strength. Motor function was recorded for each leg resulting in 0 to 14 points. Improvement or deterioration of motor function was defined as a change of two or more points.
In the present study, additional separate analyses were performed for patients with a poor survival prognosis $(n=111)$ and those patients with an intermediate survival prognosis $(n=92)$. The survival prognosis of each patient was estimated with a validated instrument developed specifically for patients irradiated for MSCC (7). Patient characteristics of both cohorts are summarized in Table I (poor prognosis group) and Table II (intermediate prognosis group).

Statistical considerations. The primary endpoint was OR with respect to motor deficits at 1 month following radiotherapy. In addition, the effect of radiotherapy on motor function (improvement, no further progression, deterioration) was evaluated with the ordered logit model, and post-radiotherapy ambulatory rates were compared with the Chi-square test. OR, effect of radiotherapy on motor function and post-treatment ambulatory rates were evaluated directly and at 1,3 and 6 months following radiotherapy. $p$-Values of less than 0.05 were considered significant. LPFS and OS were referenced from the last day of radiotherapy. LPFS was defined as no deterioration of motor deficits during or directly after radiotherapy and no in-field recurrence of MSCC during follow up. The analyses of LPFS and OS were performed with the Kaplan-Meier-method and the log-rank test (10). Again, $p$ values of less than 0.05 were regarded significant.

\section{Results}

Patients with poor survival prognoses. The OR rates after $5 \times 4 \mathrm{~Gy}$ and $10 \times 3 \mathrm{~Gy}$ were $82 \%$ (45/55 patients) vs. $79 \%$ 
(37/47 patients) directly after radiotherapy ( $p=0.86), 85 \%$ (34/40 patients) vs. $85 \%$ (28/33 patients) at 1 month following radiotherapy $(p=0.99), 100 \%$ (18/18 patients) $v s$. $87 \%$ (14/16 patients) at 3 months following radiotherapy ( $p=0.70$ ), and $100 \%$ (12/12 patients) vs. 89\% (8/9 patients) at 6 months following radiotherapy $(p=0.79)$. The rates of improvement, no further progression and deterioration of motor deficits assessed directly and 1 month, 3 months and 6 months after radiotherapy are given in Figure 1 . The posttreatment ambulatory rates after $5 \times 4 \mathrm{~Gy}$ and $10 \times 3 \mathrm{~Gy}$ were $53 \%$ (29/55 patients) vs. $51 \%$ (24/47 patients) directly after radiotherapy ( $p=0.91), 60 \%$ (24/40 patients) vs. $64 \%(21 / 33$ patients) at 1 month following radiotherapy ( $p=0.83), 72 \%$ (13/18 patients) vs. $56 \%$ (9/16 patients) at 3 months following radiotherapy ( $p=0.55)$, and $75 \%$ ( $9 / 12$ patients) vs. 78\% (7/9 patients) at 6 months following radiotherapy ( $p=0.96$ ).

The LPFS rates at 3 and 6 months were $75 \%$ vs. $75 \%$, respectively, after $5 \times 4 \mathrm{~Gy}$ and $77 \%$ vs. $69 \%$, respectively, after $10 \times 3 \mathrm{~Gy}(p=0.74)$. Median OS times were 2 months and 2 months, respectively. The OS rates at 3 and 6 months were $31 \%$ vs. $26 \%$, respectively, after $5 \times 4$ Gy and $30 \%$ vs. $19 \%$ after $10 \times 3 \mathrm{~Gy}(p=0.43)$. The corresponding Kaplan-Meier curves for both LPFS and OS are given in Figure 2.

Patients with intermediate survival prognoses. OR rates after $5 \times 4$ Gy and 10×3Gy were 93\% (38/41 patients) vs. 96\% (47/49 patients) directly after radiotherapy $(p=0.88), 89 \%(34 / 38$ patients) vs. $93 \%(41 / 44$ patients) at 1 month following radiotherapy $(p=0.85), 97 \%$ (28/29 patients) vs. $97 \%$ (28/29 patients) at 3 months following radiotherapy ( $p=1.0)$, and $95 \%$ (20/21 patients) vs. $100 \%$ (21/21 patients) at 6 months following radiotherapy $(p=0.88)$. The rates of improvement, no further progression and deterioration of motor deficits are shown in Figure 3. Post-treatment ambulatory rates after 5×4Gy and 10×3Gy were 78\% (32/41 patients) vs. 78\% (38/49 patients) directly after radiotherapy $(p=0.98), 84 \%(32 / 38$ patients) vs. 82\% (36/44 patients) at 1 month $(p=0.90), 86 \%$ (25/29 patients) vs. $83 \%$ (24/29 patients) at 3 months ( $p=0.89$ ), and $86 \%$ (18/21 patients) vs. $86 \%$ (18/21 patients) at 6 months following radiotherapy $(p=1.0)$.

LPFS rates at 3 and 6 months were $82 \%$ vs. 79\%, respectively, after $5 \times 4 \mathrm{~Gy}$ and $92 \% v s .92 \%$, respectively, after $10 \times 3$ Gy $(p=0.17)$. Median OS times were $>6$ months and $>6$ months, respectively. OS rates at 3 and 6 months were $74 \%$ vs. $65 \%$, respectively, after $5 \times 4 \mathrm{~Gy}$ and $77 \% v s .58 \%$, respectively, after $10 \times 3 \mathrm{~Gy}(p=0.65)$. The corresponding Kaplan-Meier curves for both LPFS and OS are given in Figure 4.

\section{Discussion}

Many patients with MSCC present in a reduced performance status and are not fit enough to withstand decompressive surgery or have a very radiosensitive primary tumor not
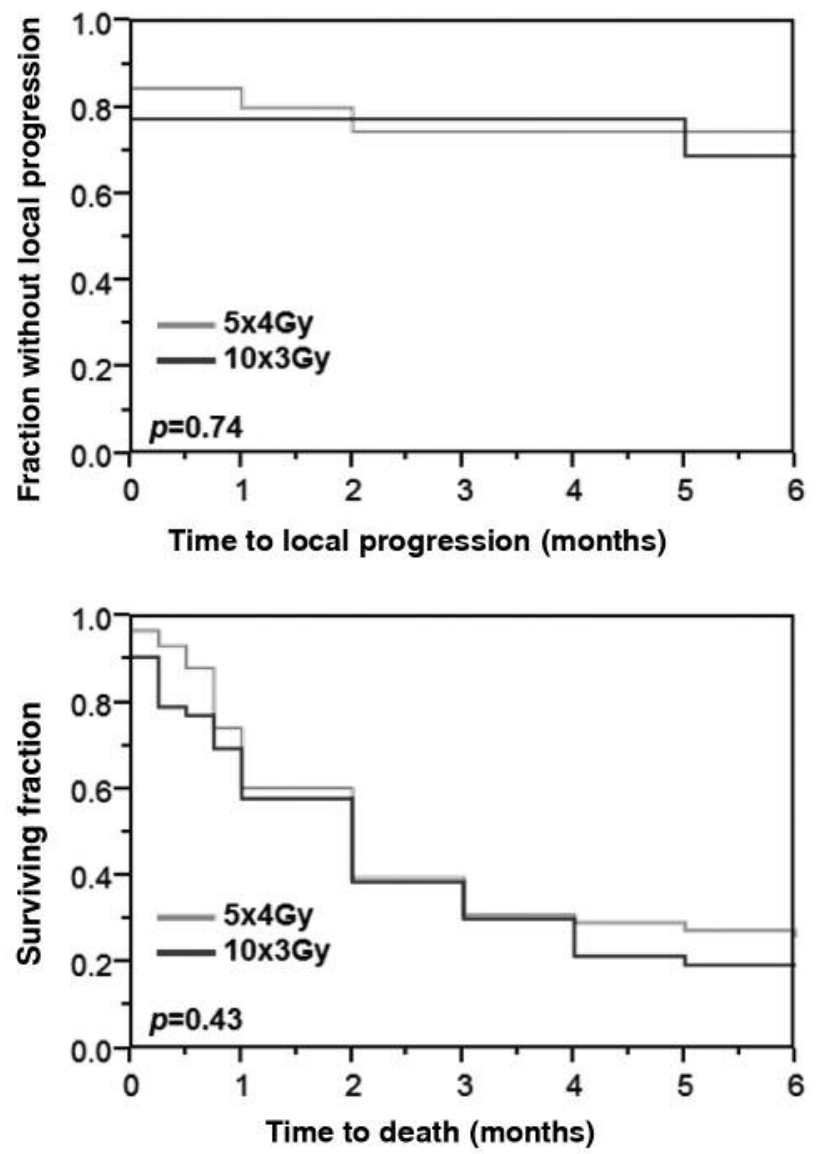

Figure 2. Patients with poor survival prognoses: Comparison of $5 \times 4 G y$ and $10 \times 3 G y$ for local progression-free survival (top) and survival (bottom).

requiring upfront surgery $(3,11-15)$. Therefore, the majority of patients with MSCC receive radiotherapy plus/minus dexamethasone. If patients are assigned to radiotherapy, several fractionation regimens are available including singlefraction regimens, short-course multi-fraction regimens lasting about 1 week and longer-course regimens lasting 2-4 weeks $(1,2)$. The optimal individual regimen should take into account the patient's survival prognosis. According to a scoring system developed to predict the probability to survive at least 6 months following radiotherapy for MSCC, three major prognostic groups (20-30 points, $31-35$ points and 36-45 points) were identified with 6-month survival rates of $9 \%, 48 \%$ and $93 \%$, respectively $(p<0.0001)(7,16)$. LPFS is another important endpoint, which also includes freedom from an in-field recurrence of MSCC in the irradiated part of the spine. In-field recurrences are often difficult to treat, because spinal surgery may not be possible and a second course of radiotherapy may exceed the tolerance dose of the spinal cord and lead to radiation myelopathy associated with 


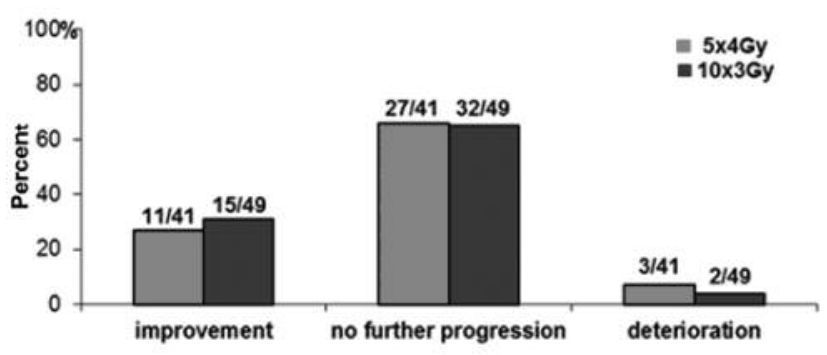

Effect on motor function directly after RT $(p=0.56)$

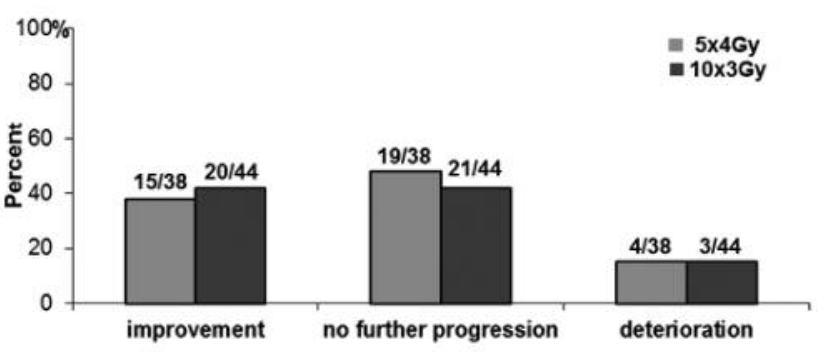

Effect on motor function at 1 month after RT $(p=0.51)$

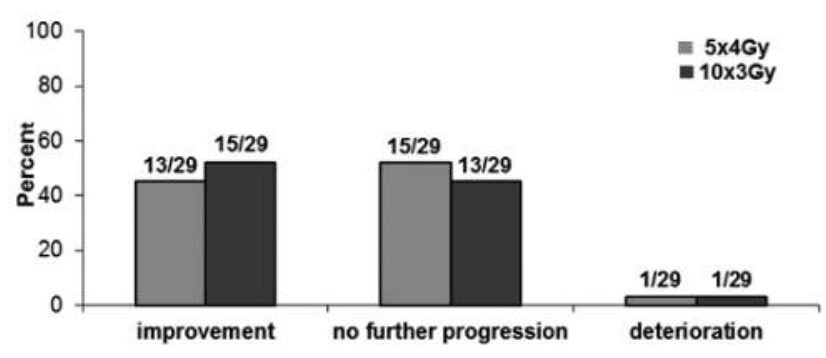

Effect on motor function at 3 months after RT $(p=0.62)$

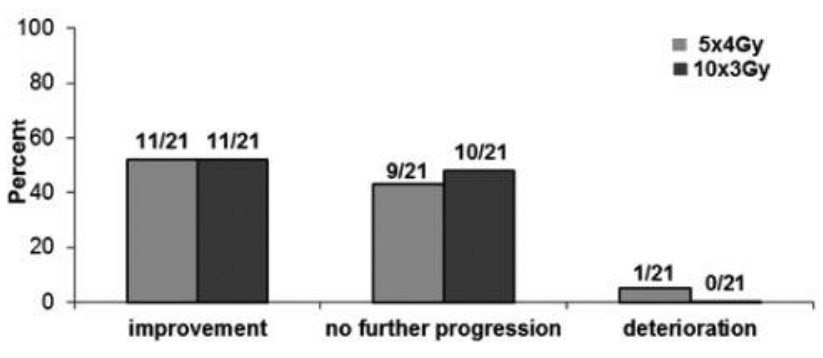

Effect on motor function at 6 months after RT $(p=0.88)$

Figure 3. Patients with intermediate survival prognoses: Comparison of $5 \times 4 G y$ and $10 \times 3 G y$ for the effect on motor function (improvement, no further progression, deterioration) directly (A), at 1 month $(B)$, at 3 months $(C)$, and at 6 months $(D)$ after radiotherapy.

severe neurologic deficits (17-19). Therefore, in-field recurrences are best avoided. In 2005, a large retrospective study suggested that in-field recurrences occur significantly more often after single-fraction $(1 \times 8 \mathrm{~Gy})$ or short-course multi-fraction $(5 \times 4$ Gy over 1 week) radiotherapy than after longer-course radiotherapy including $10 \times 3$ Gy over 2 weeks $(p<0.001)$ (20). These results were confirmed in the prospective SCORE-1 study, which compared two unselected series of patients irradiated for MSCC (8). Patients treated in the Netherlands received $1 \times 8$ Gy or $5 \times 4$ Gy $(n=131)$ and patients treated in Germany longer-course radiotherapy with $10 \times 3 \mathrm{~Gy}, 15 \times 2.5 \mathrm{~Gy}$ or $20 \times 2 \mathrm{~Gy}(\mathrm{n}=134)$. One-year local control rates were $81 \%$ after longer-course irradiation and $61 \%$ after $1 \times 8 \mathrm{~Gy} / 5 \times 4 \mathrm{~Gy}$, respectively $(p=0.005)$. This difference was also significant on multivariate analysis $(p=0.018)$. Since the risk of in-field recurrences increases with lifetime, patients with a more favorable survival prognosis should receive longer-course radiotherapy. Moreover, in a matched-pair study of 382 patients with MSCC, $15 \times 2.5 \mathrm{~Gy}$ and $20 \times 2 \mathrm{~Gy}$ resulted in significantly better local control $(92 \%$ vs. $71 \%, p=0.012)$ and survival $(68 \%$ vs. $53 \%, p=0.032)$ at 2 years than $10 \times 3 \mathrm{~Gy}$ in patients with a very favorable survival prognosis (score of 36-45 points) (21). The results regarding local control and survival were also significant on multivariate analyses. When interpreting the data of this matched-pair study, one has to be aware that the data were retrospectively collected. However, patients of both groups were matched 1:1 for ten important potential prognostic factors. The results of these studies suggest that patients with very favorable survival prognoses should not be irradiated with $1 \times 8 \mathrm{~Gy}$ or $5 \times 4 \mathrm{~Gy}$.

However, the situation would be different for patients with a poor or intermediate survival prognosis. For these patients, local control is less important than in those with very favorable prognoses, since many of these patients do not live long enough to experience an in-field recurrence. A radiotherapy regimen with less fractions and a shorter overall treatment time would result in the patients spending less time in treatment and more time with relatives and friends. Furthermore, for patients suffering from pain and neurologic deficits, a radiation session may cause discomfort. Short-course regimens could only be recommended if they were similarly effective as longer-course regimens. A few randomized trials compared fractionation regimens to evaluate if a reduction of number of fractions and treatment time is feasible and efficacious.

In 2005 , a phase III trial from Italy compared $2 \times 8 \mathrm{~Gy}$ with a gap of 6 days between the two fractions to a split-course regimen of $3 \times 5 \mathrm{~Gy}$ followed by 4 days without treatment and 
$5 \times 3 \mathrm{~Gy}$ (overall treatment time of 2 weeks) in 276 patients with MSCC and poor survival prognoses (22). Following radiotherapy, $68 \%$ and $71 \%$ of the patients, respectively, were able to walk. Median duration of the improvement of motor function was 3.5 months in both groups. In another Italian phase III trial, 2 fractions of 8 Gy given on days 1 and 7 were compared to a single fraction of $8 \mathrm{~Gy}$ in 303 patients with MSCC and a short expected survival time (23). Response rates were similar in both groups, and median duration times of response were 5 months after $2 \times 8 \mathrm{~Gy}$ and 4.5 months after $1 \times 8 \mathrm{~Gy}$, respectively $(p=0.4)$. Since the split-course regimen and $2 \times 8 \mathrm{~Gy}$ with 4 days rest are very rarely used outside Italy, the results of both trials cannot be generalized to other countries. The third randomized trial (ICORG 05-03), a non-inferiority trial from the Republic of Ireland compared $1 \times 10 \mathrm{~Gy}$ to $5 \times 4 \mathrm{~Gy}$ over 1 week 115 eligible patients with MSCC and a poor expected survival (5). Improvement/stability rates of mobility at 5 weeks were $78.9 \%$ after $1 \times 10 \mathrm{~Gy}$ and $68.4 \%$ after $5 \times 4 \mathrm{~Gy}$, respectively (difference not significant). Mobility deterioration-free survival times were 1.4 months in both groups. The most recent phase III trial (SCORAD III) compared $1 \times 8 \mathrm{~Gy}$ to $5 \times 4 G y$ over 1 week in 688 Patients with MSCC (4). Median survival in the entire cohort was only about 3 months. Primary endpoint was ambulatory status at 8 weeks following randomization; the non-inferiority margin $(1 \times 8 \mathrm{~Gy}$ vs. $5 \times 4 \mathrm{~Gy})$ was $11 \%$. Of those patients evaluable at 8 weeks, $69.5 \%$ (114 of 164 patients) after $1 \times 8 \mathrm{~Gy}$ and $73.3 \%$ (129 of 176 patients) were ambulatory with or without aid.

Our own phase III trial (SCORE-2) compared the most common regimens for MSCC, $5 \times 4 \mathrm{~Gy}$ over 1 week and $10 \times 3$ Gy over 2 weeks, in 203 patients (6). In contrast to the other four trials $(4,5,22,23)$, the SCORE-2 trial included both patients with poor and intermediate survival prognoses. According to its results, 5x4Gy was not significantly inferior to $10 \times 3 \mathrm{~Gy}$ with respect to OR, effect of radiotherapy on motor function and post-treatment ambulatory rates directly and at 1, 3 and 6 months after radiotherapy. Six-month LPFS (75.2\% vs. 81.8\%, $p=0.51)$ and 6-month survival (42.3\% vs. $37.8 \%, p=0.68)$ were also not significantly different. Two previous studies suggested that longer-course regimens such as $10 \times 3 \mathrm{~Gy}$ lead to a better local control of MSCC or LPFS than $5 \times 4 \mathrm{~Gy}(8,20)$. This benefit appears to be of most value to patients with a better survival prognosis, since the risk of an in-field recurrence of MSCC increases with time after radiotherapy and a patient would have to live long enough to be at risk. In a previous study, median survival times for patients with poor and intermediate survival prognoses were 2.5 and 5.5 months, respectively (7). It may well be that the non-inferiority of $5 \times 4 \mathrm{~Gy}$ to $10 \times 3 \mathrm{~Gy}$ in the SCORE- 2 trial regarding LPFS was caused by the patients with poor survival prognoses and may not apply to those with intermediate prognoses. Therefore, the present study was initiated, and
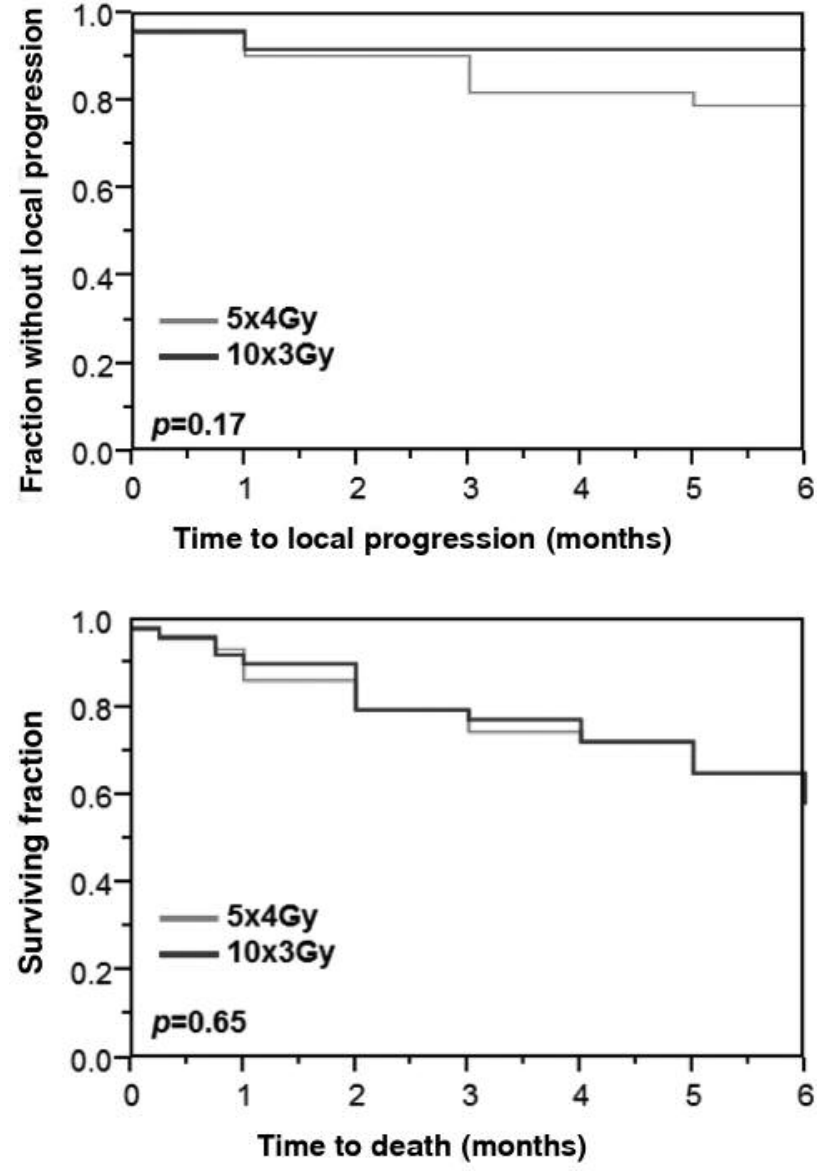

Figure 4. Patients with intermediate survival prognoses: Comparison of $5 \times 4 G y$ and $10 \times 3 G y$ for local progression-free survival (top) and survival (bottom).

these subgroup analyses of the SCORE-2 cohort were performed. The data revealed the non-inferiority of $5 \times 4 \mathrm{~Gy}$ to $10 \times 3 \mathrm{~Gy}$ regarding all investigated endpoints that was irrespective of the patients' survival prognoses (poor or intermediate). Thus, patients with intermediate prognoses (3135 points on the survival score) may be treated with $5 \times 4 \mathrm{~Gy}$ instead of $10 \times 3 \mathrm{~Gy}$, which results in fewer hospital visits (7). For patients with poor estimated survival (20-30 points), $1 \times 8$ Gy or $1 \times 10$ Gy is a reasonable option, as two randomized trials demonstrated that single-fraction radiotherapy was not inferior to $5 \mathrm{x} 4 \mathrm{~Gy}$ in these patients $(4,5)$. In contrast, patients with a very favorable survival prognosis (36-45 points) appear better treated with longer-course radiotherapy including total doses greater than 30Gy (21).

In summary, according to subgroup analyses, $5 \times 4 \mathrm{~Gy}$ was not inferior to $10 \times 3 \mathrm{~Gy}$ for MSCC in both poor- and intermediate-risk patients. Thus, $5 \times 4 \mathrm{~Gy}$ appears appropriate for patients with intermediate prognoses. Patients with poor 
expected survival may be treated with $1 \times 8 \mathrm{~Gy}$ or $1 \times 10 \mathrm{~Gy}$, since randomized trials demonstrated these regimens are not inferior to $5 \times 4 \mathrm{~Gy}$ in poor-risk patients.

\section{Conflicts of Interest}

On behalf of all Authors, the corresponding Author states that there is no conflict of interest related to this study.

\section{References}

1 Prasad D and Schiff D: Malignant spinal cord compression. Lancet Oncol 6: 15-24, 2005.

2 Rades D and Abrahm JL: The role of radiotherapy for metastatic epidural spinal cord compression. Nat Rev Clin Oncol 7: 590598, 2010.

3 Patchell R, Tibbs PA, Regine WF, Payne R, Saris S, Kryscio RJ, Mohiuddin $\mathrm{M}$ and Young B: Direct decompressive surgical resection in the treatment of spinal cord compression caused by metastatic cancer: a randomised trial. Lancet 366: 643-648, 2005.

4 Hoskin P, Misra V, Hopkins K, Holt T, Brown G, Arnott S, Thomas SS, Reczko K, Beare S, Lopes A and Forsyth S: SCORAD III: Randomized noninferiority phase III trial of single-dose radiotherapy (RT) compared to multifraction RT in patients (pts) with metastatic spinal canal compression (SCC). J Clin Oncol 35(suppl): abstr LBA10004, 2017.

5 Thirion P, O'Sullivan L, Clayton-Lea A, Small C, McArdle O, Kelly P, Parker I, O'Sullivan J, Hacking D, Collins C, Pomeroy M and Moriarty M: ICORG 05-03: Prospective randomized noninferiority phase 3 trial comparing two radiation schedules in malignant spinal cord compression not proceeding with surgical decompression. Int J Radiat Oncol Biol Phys 90: 1263-1264, 2014.

6 Rades D, Šegedin B, Conde-Moreno AJ, Garcia R, Perpar A, Metz M, Badakhshi H, Schreiber A, Nitsche M, Hipp P, Schulze W, Adamietz IA, Norkus D, Rudat V, Cacicedo J and Schild SE: Radiotherapy with 4 Gy $\times 5$ versus 3 Gy $\times 10$ for metastatic epidural spinal cord compression: Final results of the SCORE-2 Trial (ARO 2009/01). J Clin Oncol 34: 597-602, 2016.

7 Rades D, Dunst J and Schild SE: The first score predicting overall survival in patients with metastatic spinal cord compression. Cancer 112: 157-161, 2008.

8 Rades D, Lange M, Veninga T, Stalpers LJ, Bajrovic A, Adamietz IA, Rudat V and Schild SE: Final results of a prospective study comparing the local control of short-course and long-course radiotherapy for metastatic spinal cord compression. Int J Radiat Oncol Biol Phys 79: 524-530, 2011.

9 Baskin DS: Spinal cord injury. In Evans RW, editor. Neurology and trauma, Philadelphia: WB Saunders, 276-299, 1996

10 Kaplan EL and Meier P: Non-parametric estimation from incomplete observations. J Am Stat Assoc 53: 457-481, 1958.

11 Bolm L, Janssen S, Bartscht T and Rades D: Radiotherapy alone for malignant spinal cord compression in young men with seminoma. Anticancer Res 36: 2033-2034, 2016.

12 Rades D, Conde-Moreno AJ, Cacicedo J, Szegedin B and Schild SE: Estimating the survival of elderly patients with renal cell carcinoma presenting with malignant spinal cord compression. Anticancer Res 36: 409-413, 2016.
13 Janssen S, Bartscht T and Rades D: Prognosis of patients with metastatic spinal cord compression from adrenocortical carcinoma. In Vivo 30: 717-719, 2016.

14 Rades D, Bartscht T, Janssen S, Bajrovic A, Segedin B and Schild SE: Forecasting survival probabilities after radiotherapy of metastatic epidural spinal cord compression from colorectal cancer in the elderly. Anticancer Res 36: 1829-1833, 2016.

15 Janssen S, Bajrovic A, Schild SE and Rades D: A scoring instrument to predict the survival prognoses of patients with metastatic epidural spinal cord compression from gynecological malignancies. Anticancer Res 36: 5469-5472, 2016.

16 Rades D, Douglas S, Veninga T, Stalpers LJ, Hoskin PJ, Bajrovic A, Adamietz IA, Basic H, Dunst J and Schild SE: Validation and simplification of a score predicting survival in patients irradiated for metastatic spinal cord compression. Cancer 116: 3670-3673, 2010.

17 Marks LB, Yorke ED, Jackson A, Ten Haken RK, Constine LS, Eisbruch A, Bentzen SM, Nam J and Deasy JO: Use of normal tissue complication probability models in the clinic. Int J Radiat Oncol Biol Phys 76(3 Suppl): S10-19, 2010.

18 Emami B, Lyman J, Brown A, Coia L, Goitein M, Munzenrider JE, Shank B, Solin LJ and Wesson M: Tolerance of normal tissue to therapeutic irradiation. Int J Radiat Oncol Biol Phys 21: 109-122, 1991

19 Emami B: Tolerance of the normal tissue to therapeutic irradiation. Rep Radiother Oncol 1: 35-48, 2013.

20 Rades D, Stalpers LJA, Veninga T, Schulte R, Hoskin PJ, Obralic N, Bajrovic A, Rudat V, Schwarz R, Hulshof MC, Poortmans $\mathrm{P}$ and Schild SE: Evaluation of five radiation schedules and prognostic factors for metastatic spinal cord compression in a series of 1304 patients. J Clin Oncol 23: 33663375, 2005.

21 Rades D, Panzner A, Rudat V, Karstens JH and Schild SE: Dose escalation of radiotherapy for metastatic spinal cord compression (MSCC) in patients with relatively favorable survival prognosis. Strahlenther Onkol 187: 729-735, 2011.

22 Maranzano E, Bellavita R, Rossi R, De Angelis V, Frattegiani A, Bagnoli R, Mignogna M, Beneventi S, Lupattelli M, Ponticelli $\mathrm{P}$, Biti GP and Latini P: Short-course versus split-course radiotherapy in metastatic spinal cord compression: results of a phase III, randomized, multicenter trial. J Clin Oncol 23: 3358$3365,2005$.

23 Maranzano E, Trippa F, Casale M, Costantini S, Lupattelli M, Bellavita R, Marafioti L, Pergolizzi S, Santacaterina A, Mignogna M, Silvano $G$ and Fusco V: 8Gy single-dose radiotherapy is effective in metastatic spinal cord compression: results of a phase III randomized multicentre Italian trial. Radiother Oncol 93: 174-179, 2009.

Received November 13, 2017

Revised November 27, 2017

Accepted November 28, 2017 